\title{
Arsenic and Other Elements Determination in Seawater Using Coprecipitation and Standard Mode Inductively Coupled Plasma Mass Spectrometry
}

\author{
Vitor N. da Conceição, ${ }^{a}$ Taynara G. Campos, ${ }^{a}$ Bruna M. Dalfior, ${ }^{a}$ Otávio A. Heringer ${ }^{b}$ \\ Geisamanda P. Brandão ${ }^{a}$ and Maria Tereza W. D. Carneiro ${ }^{\circledR} *, a$ \\ ${ }^{a}$ Laboratório de Espectrometria Atômica (LEA)/LabPetro, Departamento de Química, \\ Universidade Federal do Espírito Santo, Av. Fernando Ferrari, 514, Goiabeiras, \\ 29075-910 Vitória-ES, Brazil
}

${ }^{b}$ Departamento de Pesquisa e Desenvolvimento, Tommasi Analitica, Av. Arara Azul, 180, Novo Horizonte, 29163-306 Serra-ES, Brazil

\begin{abstract}
The present work aims the determination of $\mathrm{As}, \mathrm{Co}, \mathrm{Cr}, \mathrm{Cu}, \mathrm{Mn}$ and $\mathrm{Pb}$ in seawater samples using coprecipitation extraction procedure before standard mode inductively coupled plasma mass spectrometry (ICP-MS) (no collision/reaction cell). The coprecipitation procedure is based on the precipitation of $\mathrm{Mg}(\mathrm{OH})_{2}$ from the reaction of the $\mathrm{Mg}^{2+}$ ions (present into the seawater) with ammonia added to the sample. Central composite design, desirability function, and response surface methodology were used to optimize the coprecipitation procedure. The optimum values obtained were $1200 \mu \mathrm{L}$ of aqueous ammonia, $30 \mathrm{~min}$ of centrifugation time and $400 \mu \mathrm{L}$ of nitric acid. The procedure obtained showed low limits of detection since good preconcentration factors were obtained. Good accuracy was also obtained when the reference material Trace Metals 1 in seawater was evaluated. Thus, the proposed procedure can be considered a good strategy for the determination of $\mathrm{As}, \mathrm{Co}, \mathrm{Cr}, \mathrm{Cu}, \mathrm{Mn}$ and $\mathrm{Pb}$ in seawater by ICP-MS, due to its simplicity, low cost, high analytical frequency, besides the good sensitivity and accuracy achieved.
\end{abstract}

Keywords: seawater, arsenic, coprecipitation, ICP-MS

\section{Introduction}

The oceans are considered one of the main sources of biological activity, biodiversity and biomass production. However, in the last decades, the quality of these aquatic systems has been modified at different scales mainly because of anthropic activities that contribute to the input contaminants in these sites. ${ }^{1}$ Some trace elements as arsenic, lead and chromium are among the contaminants most investigated in seawater and the increasing of these elements in aquatic systems can cause their accumulation in aquatic biota, causing serious ecological damage. ${ }^{2,3}$ Thus, it becomes relevant to characterize water bodies concerning trace elements.

Among the methods used for trace elements determination in seawater, inductively coupled plasma mass spectrometry (ICP-MS) has a great emphasis due to its high sensitivity, low limits of detection and quantification, besides the optimum analytical frequency. ${ }^{4,5}$ However, the

*e-mail: mariacarneiro@hotmail.com analysis of saline water by ICP-MS is a challenge, since the $\mathrm{NaCl}$ matrix can generate numerous interferences. ${ }^{6}$ The polyatomic interferences caused by the matrix components are significant for arsenic $\left({ }^{40} \mathrm{Ar}^{35} \mathrm{Cl}^{+}\right.$on $\left.{ }^{75} \mathrm{As}^{+}\right)$, copper $\left({ }^{40} \mathrm{Ar}^{23} \mathrm{Na}^{+}\right.$on $\left.{ }^{63} \mathrm{Cu}^{+}\right)$and chromium $\left({ }^{1} \mathrm{H}^{16} \mathrm{O}^{35} \mathrm{Cl}^{+}\right.$on $\left.{ }^{52} \mathrm{Cr}^{+}\right)$, for example. ${ }^{7}$ Also, the high salt concentration present in seawater results in non-spectral interferences, causing variations, suppression or enhancement, in the signal. ${ }^{8}$ Therefore, to minimize these interferences in seawater analysis by ICP-MS, some approaches should be used such as sample dilution, matrix modification or separation, analyte addition or internal standard calibration procedure, kinetic energy discrimination (KED) or dynamic reaction cell (DRC). ${ }^{9}$ Pinheiro et al..$^{10}$ evaluated different strategies to determine several elements in seawater using ICP-MS. The authors concluded that the usage of collision gas $\mathrm{He}$ was necessary to determine $\mathrm{As}, \mathrm{Cu}$ and $\mathrm{Cr}$ with good limits of detection and accuracy. To overcome the interferences present in seawater analysis by ICP-MS, the matrix separation analytical procedures are a good alternative to correct both non-spectral and spectral interferences, 
beyond the preconcentration capabilities and the limit of detection enhancement. Among these procedures, solidphase extraction and coprecipitation are the most used. ${ }^{11-20}$

Coprecipitation is a good strategy due to its greater simplicity. Ardini et al..$^{15}$ determined $\mathrm{Cr}, \mathrm{Fe}, \mathrm{Mn}, \mathrm{Pb}$ and $\mathrm{Zn}$ in seawater using magnesium hydroxide coprecipitation as sample preparation. The formation of $\mathrm{Mg}(\mathrm{OH})_{2}$ was induced by ammonia and the resulting precipitate was dissolved using $5 \mathrm{~mL}$ of dilute nitric acid and the detection was realized by DRC-ICP-MS. ${ }^{15}$ The procedure resulted in a preconcentration factor of 10 -fold and analyte addition was used for calibration. $\mathrm{Mg}(\mathrm{OH})_{2}$ coprecipitation with ammonia was also used by Yang et al. ${ }^{16}$ for the extraction of $\mathrm{Cu}, \mathrm{Zn}, \mathrm{Co}$ and $\mathrm{V}$ in seawater samples. However, in this work, a volume of $0.5 \mathrm{~mL}$ of seawater was used and the precipitate formed was dissolved with dilute $\mathrm{HCl}$ to a final volume of $5 \mathrm{~mL}$. The determination of the elements was performed by ICP-MS using standard addition calibration and recoveries ranging from 67 to $96 \%$. Arslan et al. ${ }^{17}$ employed triethylamine (TEA) for the precipitation of $\mathrm{Mg}(\mathrm{OH})_{2}$ and the extraction of many trace elements in seawater and estuarine water. The main objective of the authors was to substitute ammonia for TEA to avoid the formation of ammonia complexes and to increase the number of elements extracted in comparison with other works. The procedure was repeated three times for better extraction of the analytes and ICP-MS with reaction/ collision cell was used in the analysis, for the minimization of interference. The calibration was performed with an analytical curve employing internal standardization. As an alternative, the present work proposes the extraction of several elements ( $\mathrm{Co}, \mathrm{Cr}, \mathrm{Cu}, \mathrm{Mn}$ and $\mathrm{Pb}$ ), including arsenic, using the coprecipitation trough the reaction of the ions $\mathrm{Mg}^{2+}$ present in seawater with ammonia to form $\mathrm{Mg}(\mathrm{OH})_{2}$, and posterior determination by ICP-MS. The proposed procedure does not require the use of special gas for collision/reaction to overcome polyatomic interferences and the calibration was done only with internal standardization. For the establishment of the coprecipitation methodology, multivariate optimization was used using the central composite design, desirability function and response surface methodology.

\section{Experimental}

\section{Instrumentation}

The determination of $\mathrm{As}, \mathrm{Co}, \mathrm{Cr}, \mathrm{Cu}, \mathrm{Mn}$ and $\mathrm{Pb}$ was performed by inductively coupled plasma mass spectrometer, model Nexion 300D (PerkinElmer, USA) with the operational conditions described in Table 1 . The premier argon gas with a purity of $99.9992 \%$ (Air Products, Brazil) was used for the generation and maintenance of the plasma, nebulization of the sample and as auxiliary gas. The coprecipitation process was performed with the aid of a microprocessor centrifuge (Chimis, Brazil) and vacuum pump (Vacuubrand, Germany).

Table 1. Instrumental conditions of ICP-MS

\begin{tabular}{lc}
\hline Operating condition & \\
\hline Spray chamber & borosilicate glass baffled cyclonic \\
Nebulizer & concentric Meinhard, type C \\
Cone & nickel \\
Torch & 1450 \\
RF power / W & 1.20 \\
Auxiliary gas flow rate / $\left(\mathrm{L} \mathrm{min}^{-1}\right)$ & 16.00 \\
Plasma gas flow rate / $(\mathrm{L} \mathrm{min}-1)$ & 1.1 \\
Nebulizer gas flow rate / $\left(\mathrm{L} \mathrm{min}^{-1}\right)$ & 3 \\
Scans/replicate & ${ }^{3}$ \\
Isotopes measured & ${ }^{75} \mathrm{As},{ }^{59} \mathrm{Co},{ }^{53} \mathrm{Cr},{ }^{63} \mathrm{Cu},{ }^{55} \mathrm{Mn},{ }^{208} \mathrm{~Pb}$ \\
Internal standard & ${ }^{45} \mathrm{Sc},{ }^{89} \mathrm{Y},{ }^{103} \mathrm{Rh}$ \\
\hline
\end{tabular}

Reagents and materials

The decontamination of materials and preparation of samples were done using ultrapure water with a resistivity of $18.2 \mathrm{M} \Omega \mathrm{cm}$, Purelab Ultra system (Elga, High Wycombe, $\mathrm{UK}$ ) and $\mathrm{HNO}_{3} 68 \% \mathrm{~m} / \mathrm{m}$ (Neon, Suzano, Brazil). The acid used was sub-boiling distilled using Distilacid BSB939 IR (Berghof, Eningen unter Achalm, Germany).

All materials used in this study were decontaminated with Extran MA 02 neutral (Merck, Rio de Janeiro, Brazil), washed with water and then left in a bath of $15 \% \mathrm{v} / \mathrm{v} \mathrm{HNO}_{3}$ for $24 \mathrm{~h}$. After this period, the materials were washed with ultrapure water.

Quantitative filter paper (UNIFIL, Ruppichteroth, Germany), cellulose acetate membrane (47 mm diameter and pore of $0.45 \mu \mathrm{m}$, Analítica, São Paulo, Brazil, Brazil), $50 \mathrm{~mL}$ polypropylene tubes (Sarstedt, Nümbrecht, Germany), and aqueous $\mathrm{NH}_{3}(32 \% \mathrm{~m} / \mathrm{v}$, Vetec, Duque de Caxias, Brazil) were used for the preparation of the samples. Sodium chloride $(99 \% \mathrm{~m} / \mathrm{m}$, Dynamics, Caxias do Sul, Brazil) and magnesium sulfate (Sigma-Aldrich, Steinheim, Germany) were also used in this study.

Calibration solutions were prepared from an adequate dilution with $4 \% \mathrm{v} / \mathrm{v} \mathrm{HNO}_{3}$ of single element standards solutions (> 99.9\% m/m, Specsol, São Paulo, Brazil) with concentrations of $1000 \mathrm{mg} \mathrm{L}^{-1}$. The working range was 0.10 to $20 \mu \mathrm{g} \mathrm{\textrm {L } ^ { - 1 }}$. Sc, Y and Rh were used as internal standards (5 $\left.\mu \mathrm{g} \mathrm{L}^{-1}\right)$ prepared from a $1000 \mathrm{mg} \mathrm{L}^{-1}$ multi-element standard solution (SPC Science, Quebec, Canada). 
The determination of residual chloride ions was performed using a titrimetric method with silver nitrate ( $99 \%$ m/m, Sigma-Aldrich, Steinheim, Germany), calcium carbonate $(99 \% \mathrm{~m} / \mathrm{m}$, Sigma-Aldrich, Steinheim, Germany) and potassium chromate $(99.5 \% \mathrm{~m} / \mathrm{m}$, Sigma-Aldrich, Steinheim, Germany).

The certified reference material (CRM) Trace Metals 1 in seawater-QC (Sigma-Aldrich, Steinheim, Germany) was used to evaluate the accuracy of the analytical procedure.

\section{Multivariate optimization}

The central composite design was performed to optimize the coprecipitation procedure. The independent variables studied were $\mathrm{NH}_{3}$ volume $(\mu \mathrm{L})$; centrifugation time (min) and $\mathrm{HNO}_{3}$ volume $(\mu \mathrm{L})$. The response (dependent variable) evaluated was percentage of recovery. The mathematical model of desirability was applied to the optimization of the multiple responses, transforming them into a single response (y). For this, the recoveries (responses) were first converted to values 0 and 1 , called individual desirability (di), where 0 represents an undesirable recovery $(<60 \%$ and $>140 \%)$ and, 1 , a desirable recovery (80 to $120 \%) .{ }^{21}$ Also, it was established values between 0 and 1 , using recoveries 60 to $80 \%$ as minimum range and 120 to $140 \%$ as maximum range following the recommendations of AOAC..$^{22}$

The individual desirability $(0<\mathrm{di}<1)$ was calculated using equation 1 , where $y$ is the recovery obtained from the experiment, $\mathrm{L}$ is the lowest acceptable recovery $(60 \%)$, and $\mathrm{T}$ is the maximum acceptable recovery $(80 \%)$.

$\mathrm{di}=(\mathrm{y}-\mathrm{L}) /(\mathrm{T}-\mathrm{L})$

For the range 120 to $140 \%$, equation 2 was used to calculate the individual desirability $(0<\mathrm{di}<1)$. In this situation, $\mathrm{U}$ is the maximum acceptable recovery and $\mathrm{T}$ the lowest acceptable recovery $(120 \%)$ to the range under evaluation.

$\mathrm{di}=(\mathrm{U}-\mathrm{y}) /(\mathrm{U}-\mathrm{T})$

After the establishment of individual desirability for each element, a geometric mean of m numbers was used to obtain the global desirability (D) (equation 3).

$\mathrm{D}=\sqrt[\mathrm{m}]{\operatorname{di} 1 \times \operatorname{di} 2 \times \ldots d m}$

The mathematical model obtained was evaluated using variance analysis (ANOVA) and the establishment of optimal values was established from the response surface. ${ }^{23}$ Microsoft Office Excel 2013 and the free trail of Statistica 7.0 version $^{24}$ were used in this study.

\section{Proposed procedure}

A volume of $45 \mathrm{~mL}$ of filtered and acidified seawater sample was put into a polypropylene tube of $50 \mathrm{~mL}$, $1200 \mu \mathrm{L}$ of concentrated ammonia were added and the final volume of $50 \mathrm{~mL}$ was adjusted with ultrapure water. The content of the tube was homogenized and left to rest for $3 \mathrm{~min}$. After this reaction time, the sample was centrifugated for $30 \mathrm{~min}$ at $3000 \mathrm{rpm}$. Subsequently, the supernatant was discarded, and the precipitate was dissolved using $400 \mu \mathrm{L}$ of concentrated nitric acid. Ultrapure water was added up to $10 \mathrm{~mL}$ and the solution obtained was analyzed by ICP-MS. A scheme of the procedure is represented in Figure 1.

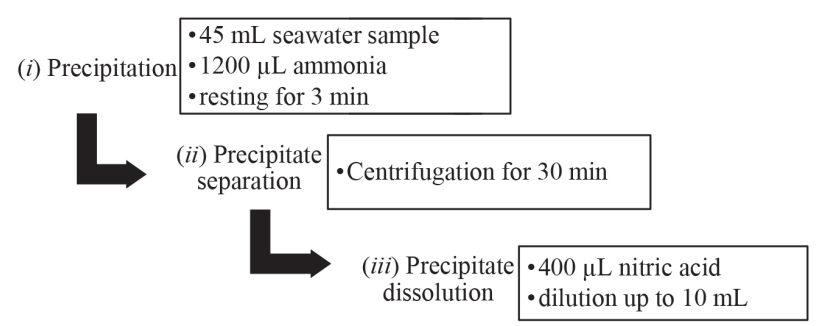

Figure 1. Scheme of the procedure of extraction of $\mathrm{As}, \mathrm{Co}, \mathrm{Cr}, \mathrm{Cu}, \mathrm{Mn}$ and $\mathrm{Pb}$ from seawater sample using $\mathrm{Mg}(\mathrm{OH})_{2}$ coprecipitation.

\section{Results and Discussion}

Multivariate optimization

The establishment of significant variables for the central composite design was carried out in advance from a complete factorial design. The significant independent variables for coprecipitation were $\mathrm{NH}_{3}$ volume $(\mu \mathrm{L})$; centrifugation time (min) and volume of $\mathrm{HNO}_{3}(\mu \mathrm{L})$.

The optimization was performed using the central composite design and the response surface methodology, which are based on the adjustment of a polynomial equation to the experimental data, describing the behavior of a data group to realize statistical prediction. ${ }^{23}$ The response used to verify the efficiency of the extraction of the analytes was recovery (in percentage).

The central composite used for the optimization of the variables resulted in 17 experiments, 8 of the factorial design, 6 related to the axial points and 3 repetitions of the central point $\left(2^{3}+2 \mathrm{k}+3\right){ }^{23}$ The recovery was used as the response variable, so the 17 experiments were performed with seawater and with seawater spiked with $2 \mu \mathrm{g} \mathrm{L} \mathrm{L}^{-1}$.

The evaluation of the quality of the model fitted was performed by analysis of variance (ANOVA). The $F$ test was used to evaluate the lack of adjustment of the model, where $f_{\text {calculated }} 3.34$ was lower than the $f_{\text {critic }} 19.3$ to a confidence level of $95 \%$, showing that the model does not 
have lack of adjustment. Besides this, the model presented a pure error low (0.0662) and a good regression coefficient $\left(\mathrm{R}^{2}=0.790\right)$, which indicated $79 \%$ of the relationship between the independent factors and the response variable can be explained.

Based on the global desirability, the response surfaces of the model were constructed (Figure S1, Supplementary Information section) to evaluate the behavior of the data and to make predictions statistically valid. ${ }^{25}$ Thus, the critical points of each variable were $1200 \mu \mathrm{L}$ of aqueous ammonia, 30 min for centrifugation time and $400 \mu \mathrm{L}$ of nitric acid.

\section{Sample volume}

The coprecipitation procedure was optimized using a sample volume of $45 \mathrm{~mL}$. However, in some cases, it may be necessary to use a smaller sample volume. Thus, tests with a smaller sample volume ( 15 and $25 \mathrm{~mL})$ were performed to evaluate the efficiency of the procedure. The procedure was performed exactly as described above, only changing the initial sample volume. The recoveries obtained (87.7-123\%) indicate that a smaller sample volume can be used that is advantageous when the sample quantity available for analysis is restricted and the method of analysis has good sensitivity.

Although the coprecipitation was optimized for As, $\mathrm{Cr}, \mathrm{Cu}, \mathrm{Mn}$ and $\mathrm{Pb}$ determination, it was verified that Co determination is also possible using the proposed procedure.

\section{Extraction efficiency}

The extraction process of the analytes by coprecipitation was evaluated concerning the residual concentration of chloride ions in the solution under analysis.

The evaluation of the presence of dissolved salts as $\mathrm{NaCl}$ in solution is important because this matrix can cause numerous interferences in the ICP-MS. So, chloride ions determination in the final solution was performed by precipitation titrimetry. ${ }^{26} \mathrm{An}$ aliquot of $3.0 \mathrm{~mL}$ of the sample solution was titrated with a previously standardized silver nitrate solution $\left(0.1145 \mathrm{~mol} \mathrm{~L}^{-1}\right)$. The $\mathrm{pH}$ of the solution was adjusted to 7 with calcium carbonate.

It was verified that the residual chloride content in the solution was $25 \%$ in relation to the original seawater sample. This result indicates that with only one step the coprecipitation procedure was able to eliminate $75 \%$ of initial chloride. The proposed methodology can reduce the presence of salts and minimize the spectral and nonspectral interferences arising from the saline matrix in the analyzes by ICP-MS. Thus, the $\mathrm{NaCl}$ removal from seawater samples allows the analysis by ICP-MS with no necessity of collision/reaction cell.

\section{Preconcentration factor}

The preconcentration factor was evaluated comparing the slopes of the calibration curves, one curve was done by addition of the analytes before the coprecipitation procedure and the other one with the addition at the end of the coprecipitation procedure. The actual preconcentration factor was determined through the ratio of the slopes of the two analytical curves and their found values are varying between 89.9 and $100 \%$ of the theoretical value, i.e., 4.5.

\section{Analytical figures of merit}

The calibration was performed using internal standardization ( $\mathrm{Sc}, \mathrm{Y}$ and $\mathrm{Rh}$ ) and good coefficients of determination (greater than 0.999) were obtained. The correction with internal standards was necessary for all analytes to compensate the effects of the residual saline matrix in the analytical solution. The internal standards used were ${ }^{45} \mathrm{Sc}$ for ${ }^{53} \mathrm{Cr}$, ${ }^{89} \mathrm{Y}$ for ${ }^{75} \mathrm{As},{ }^{59} \mathrm{Co}$ and ${ }^{55} \mathrm{Mn}$, and ${ }^{103} \mathrm{Rh}$ for ${ }^{63} \mathrm{Cu}$ and ${ }^{208} \mathrm{~Pb}$.

Limits of detection (LOD) were calculated using the definitions proposed by $\operatorname{IUPAC}^{27}(\mathrm{LOD}=3 \mathrm{~s} / \mathrm{a})$, where $\mathrm{s}$ is the estimated standard deviation of blank (in this study 15 readings of preparation blank were used) and $a$ is the slope of the analytical curve. The LOD found in the proposed coprecipitation procedure were satisfactory when compared with that published in the literature (Table 2). Low limits allow determining very low concentrations for $\mathrm{As}$ and $\mathrm{Pb}$, for example, that are extremely harmful to aquatic biota.

The accuracy of the proposed procedure was evaluated using the certified reference material (CRM) and recovery tests.

The recovery test was performed by the addition of 2.5 and $5 \mu \mathrm{g} \mathrm{L}^{-1}$ of the analytes in seawater samples. The recoveries obtained (Table 3) follow the established by $\mathrm{AOAC}^{22}$ for the concentration range under study. These results indicate that the method is not affected by matrix effects.

The certified reference material (CRM) Trace Metals 1 in seawater-QC was used to evaluate the accuracy of the proposed procedure. However, as this CRM is a synthetic saline matrix ( $3.5 \% \mathrm{~m} / \mathrm{m}$ of dissolved salts) and magnesium was not present in quantity enough to be precipitate as $\mathrm{Mg}(\mathrm{OH})_{2}$, the addition of $\mathrm{Mg}^{2+}$ ions was done based on seawater composition. ${ }^{28}$ 
Table 2. Limits of detection (LOD) obtained in the proposed procedure and some published in the literature for trace elements in seawater samples by ICP-MS

\begin{tabular}{|c|c|c|c|c|c|c|c|}
\hline \multirow{2}{*}{ Methodology } & \multicolumn{6}{|c|}{ Limit of detection / $\left(\mathrm{ng} \mathrm{L}^{-1}\right)$} & \multirow{2}{*}{ Reference } \\
\hline & As & Co & $\mathrm{Cr}$ & $\mathrm{Cu}$ & $\mathrm{Mn}$ & $\mathrm{Pb}$ & \\
\hline \multirow{4}{*}{ Coprecipitation } & 1.05 & 0.02 & 3.71 & 0.14 & 0.11 & 0.07 & this work \\
\hline & 0.26 & 0.14 & 1.30 & 2.10 & - & 0.56 & 15 \\
\hline & - & 11.19 & - & 242 & - & - & 16 \\
\hline & 6 & 0.60 & 11 & 24 & 15 & 62 & 17 \\
\hline \multirow{3}{*}{ Chelating resin } & 345 & 6 & - & 36 & 5 & 17 & 11 \\
\hline & - & 0.03 & - & 0.30 & 0.60 & 0.10 & 12 \\
\hline & - & 1.10 & - & 2.60 & 4.80 & 0.74 & 14 \\
\hline
\end{tabular}

The reagents used for coprecipitation were iron and ammonium acetate for reference 15 , ammonia for reference 16 and this work, and triethylamine for reference 17.

Table 3. Recovery values obtained after the addition of analytes at two concentration levels for seawater samples

\begin{tabular}{lcccccc}
\hline $\begin{array}{l}\text { Concentration / } \\
(\mu \mathrm{g} \mathrm{L}-1)\end{array}$ & \multicolumn{9}{c}{ Recovery of analytes / \% } \\
\cline { 2 - 7 } & $\mathrm{As}$ & $\mathrm{Co}$ & $\mathrm{Cr}$ & $\mathrm{Cu}$ & $\mathrm{Mn}$ & $\mathrm{Pb}$ \\
\hline 2.5 & 83.6 & 97.3 & 125.4 & 107.3 & 84.7 & 112.7 \\
5.0 & 97.6 & 99.8 & 112.4 & 99.0 & 106.8 & 98.4 \\
\hline
\end{tabular}

The results (Table 4) show a good agreement among the certified values and the obtained values according to $\mathrm{AOAC}^{22}$ for $\mathrm{Co}, \mathrm{Cr}, \mathrm{Cu}$, and $\mathrm{Pb}$, indicating the accuracy of the proposed procedure. For As (60.5\%) and Mn (71.6\%) although the recoveries were low, they should not be disregarded, mainly due to the complexity of the matrix and the simplicity of the procedure for sample preparation. The lower recoveries values for As and Mn may suggest that a coprecipitation step should be once more realized to improve the extraction of these analytes.

\section{Real samples analysis}

Ten seawater samples from Vitória Bay, located in the state of Espírito Santo, Brazil, were used to verify the applicability of the proposed methodology in real samples. The samples were filtered and acidified, and subsequently, the methodology of coprecipitation was applied before trace elements determination by ICP-MS. The range of values obtained was 11.00-13.50 $\mu \mathrm{g} \mathrm{L}^{-1}$ for As, 0.62-0.99 $\mu \mathrm{g} \mathrm{L}^{-1}$ for $\mathrm{Co}, 30.42-43.40 \mu \mathrm{g} \mathrm{L} \mathrm{L}^{-1}$ for $\mathrm{Cr}, 6.26-8.94 \mu \mathrm{g} \mathrm{L^{-1 }}$ for $\mathrm{Cu}$, 1.41-2.00 $\mu \mathrm{g} \mathrm{L}^{-1}$ for $\mathrm{Mn}$ and 1.34-8.23 $\mu \mathrm{g} \mathrm{L}^{-1}$ for $\mathrm{Pb}$. The results obtained showed that it was able to quantify all the elements even that elements in low concentration with good precision, indicating that the proposed procedure is suitable to be used in seawater analysis in monitoring studies.

\section{Conclusions}

The multivariate optimization of the coprecipitation for $\mathrm{As}, \mathrm{Co}, \mathrm{Cr}, \mathrm{Cu}, \mathrm{Mn}$ and $\mathrm{Pb}$ determination in seawater samples by ICP-MS provided a simple, fast and accurate procedure. Low limits of detection were obtained, due to the preconcentration achieved, and are appropriate to determine the elements in seawater samples. Also, the proposed procedure has demonstrated the possibility to

Table 4. Concentration (mean \pm standard deviation, $\mathrm{n}=3$ ) of $\mathrm{As}, \mathrm{Co}, \mathrm{Cr}, \mathrm{Cu}, \mathrm{Mn}$ and $\mathrm{Pb}$ in the $\mathrm{CRM}$ metals in seawater and percentage of recoveries to certified values

\begin{tabular}{lcccccc}
\hline CRM metals in & \multicolumn{5}{c}{ Analyte $/\left(\mu \mathrm{g} \mathrm{L}^{-1}\right)$} \\
\cline { 2 - 7 } seawater & $\mathrm{As}$ & $\mathrm{Co}$ & $\mathrm{Cr}$ & $\mathrm{Cu}$ & $\mathrm{Mn}$ & $\mathrm{Pb}$ \\
\hline Certified value & $823.0 \pm 82.3$ & $647.0 \pm 64.7$ & $759.0 \pm 75.9$ & $156.0 \pm 15.6$ & $1080 \pm 108$ & $690.0 \pm 69$ \\
Obtained value & $498.3 \pm 31.6$ & $549.5 \pm 13.4$ & $803.3 \pm 4.0$ & $125.2 \pm 15.7$ & $759.3 \pm 39.9$ & $636.4 \pm 12.1$ \\
Extraction / \% & 60.5 & 85.0 & 105.8 & 80.2 & 71.6 & 92.2 \\
\hline
\end{tabular}

CRM: certified reference material. 
overcome some interferences in ICP-MS seawater analysis with no use of reaction/collision cell.

\section{Supplementary Information}

Supplementary data are available free of charge at https://jbcs.sbq.org.br as PDF file.

\section{Acknowledgments}

This work was supported by the Coordenação de Aperfeiçoamento de Pessoal de Nível Superior-Brazil (CAPES) finance code 001; Fundação de Amparo à Pesquisa do Espírito Santo-Brazil (FAPES); and LabPetro/ UFES-Laboratório de Pesquisa e Desenvolvimento de Metodologias para Análise de Petróleo.

\section{Author Contributions}

Vitor N. da Conceição was responsible for conceptualization, formal analysis, investigation, methodology, writing the original draft; Taynara G. Campos for formal analysis, methodology; Bruna M. Dalfior for conceptualization, formal analysis, methodology; Otávio A. Heringer for conceptualization, investigation, methodology; Geisamanda P. Brandão for investigation, methodology, validation; Maria Tereza W. D. Carneiro for funding acquisition, investigation, methodology, project administration, writing-review and editing.

\section{References}

1. Sandifer, P. A.; Holland, A. F.; Rowles, T. K.; Scott, G. I.; Environ. Health Perspect. 2004, 112, 454.

2. Achary, M. S.; Satpathy, K. K.; Panigrahi, S.; Mohanty, A. K.; Padhi, R. K.; Biswas, S.; Prabhu, R. K.; Iakshmi, S. V.; Panigrahy, R. C.; Food Control 2007, 72, 232.

3. Guilherme, L. R. G.; Marques, J. J.; Pierangeli, M. A. P.; Zuliani, D. Q.; Campos, M. L.; Marchi, G. In Tópicos em Ciência do Solo, vol. 4; Sociedade Brasileira de Ciência do Solo: Viçosa, 2013, p. 20.

4. Mketo, N.; Nomngongo, N.; Ngila, C.; TrAC, Trends Anal. Chem. 2016, 85, 107.

5. Pérez-Álvarez, E. P.; Garcia, R.; Barrulas, P.; Dias, C; Cabrita, M. J.; Garde-Cerdán; Food Chem. 2019, 270, 273.

6. Wang, B.; Lee, C.; Ho, T.; Talanta 2014, 128, 337.

7. Bednar, A. J.; Kirgan, R. A.; Jones, W. T.; Anal. Chim. Acta 2009, 632, 27.
8. Korvela, M.; Andersson, M.; Pettersson, J.; J. Anal. At. Spectrom. 2018, 33, 1770.

9. Illio, S. D.; Violante, N.; Majorani, C.; Petrucci, F.; Anal. Chim. Acta 2011, 698, 6.

10. Pinheiro, F. C.; Lorençatto, R.; Barros, A. I.; Amaral, C. D. B.; Nóbrega, J. A.; J. Braz. Chem. Soc. 2018, 29, 1570.

11. Sondergaard, J.; Asmund, G.; Larsen, M. M.; MethodsX 2015 , $2,323$.

12. Rahmi, D.; Zhu, Y.; Fujimori, E.; Umemura, T.; Haraguchi, H.; Talanta 2007, 72, 600.

13. Minami, T.; Konagaya, W.; Zheng, L.; Takano, S.; Sasaki, M.; Murata, R.; Nakaguchi, Y.; Sohrin, Y.; Anal. Chim. Acta 2015, $854,183$.

14. Sohrin, Y.; Urushihara, S.; Nakatsuka, S.; Kono, T.; Higo, E.; Minami, T.; Norisuye, K.; Umetani, S.; Anal. Chem. 2008, 80, 6267.

15. Ardini, F.; Magi, E.; Grotti, M.; Anal. Chim. Acta 2011, 706, 84.

16. Yang, R.; Ning, Y.; Zhang, A.; Li, Y.; Su, H.; J. Ocean Univ. China 2016, 15, 825.

17. Arslan, Z.; Oymak, T.; White, J.; Anal. Chim. Acta 2018, 1008, 18.

18. Saito, M. A.; Schneider, D. L.; Anal. Chim. Acta 2006, 565, 222.

19. Yatai, L.; Wei, G.; Zhiwei, W.; Jin, L.; Ke, Y.; Guo, Q.; Hu, S.; Microchem. J. 2016, 126, 194.

20. Quinto, F.; Golser, R.; Lagos, M.; Plaschke, M.; Schafer, T.; Steier, P.; Geckeis, H.; Anal. Chem. 2015, 87, 5766.

21. Pereira Filho, E. R.; Planejamento Fatorial em Química: Maximizando a Obtenção de Resultados; Edufscar: São Carlos, Brazil, 2015.

22. Official Methods of Analysis of AOAC International; Guidelines for Standard Method Performance Requirements, $20^{\text {th }}$ ed.; Latimer, G. W., ed.; AOAC International: Rockville, 2016.

23. Novaes, C. G.; Yamaki, R. T.; Paula, V. F.; Nascimento Jr., B. B.; Barreto, J. A.; Valesques, G. S.; Bezerra, M. A.; Rev. Virtual Quim. 2017, 9, 1184.

24. Statistica, version 7.0; StatSoft, Tulsa, OK, USA, 2004.

25. Hanrahan, G.; Lu, K.; Crit. Rev. Anal. Chem. 2006, 36, 141.

26. Skoog, D. A.; West, D. M.; Holler, F. J.; Crouch, S. R.; Fundamentals of Analytical Chemistry, $9^{\text {th }}$ ed.; Thomson Brooks: Boston, USA, 2012.

27. Mocak, J.; Bond, A. M.; Mitchell, S.; Scollary, G.; Pure Appl. Chem. 1997, 69, 297.

28. Matsuura, T.; Desalination 2001, 134, 47.

Submitted: February 17, 2020 Published online: August 21, 2020 